\title{
ANÁLISE DA RELEVÂNCIA DE INDICADORES FINANCEIROS E NÃO FINANCEIROS NA AVAL- IAÇÃO DE DESEMPENHO ORGANIZACIONAL: UM ESTUDO EXPLORATÓRIO NO SETOR BRASILEIRO DE DISTRIBUIÇÃO DE ENERGIA ELÉTRICA
}

\section{ANALYSIS OF RELEVANCE OF FINANCIAL AND NON FINANCIAL RATIOS WHEN EVAL- UATING ORGANIZATIONAL PERFORMANCE: A STUDY IN THE BRAZILIAN ELECTRIC- ITY DISTRIBUTION SECTOR}

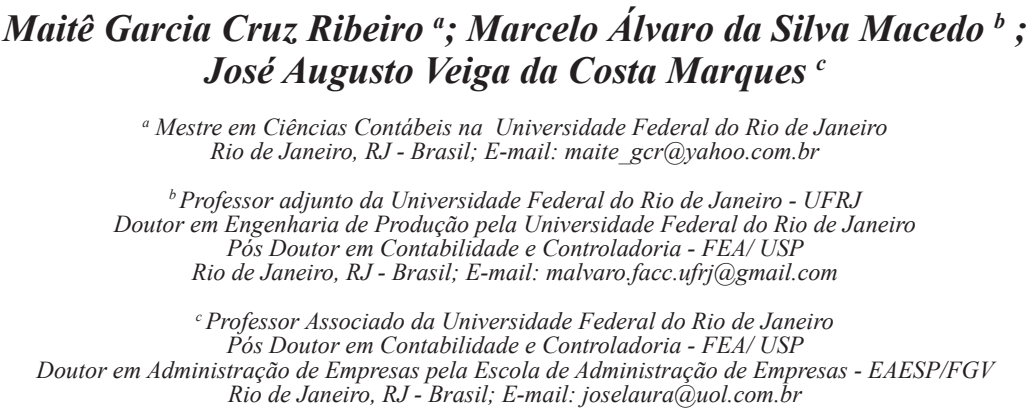

\section{Resumo}

Este artigo tem como objetivo analisar a relevância de indicadores financeiros e não financeiros na avaliação do desempenho organizacional de empresas do setor brasileiro de distribuição de energia elétrica. Para tanto, um estudo de caráter exploratório, com uso das técnicas Delphi e Análise Hierárquica (AHP) foi conduzido. Os resultados mostram que em relação à perspectiva financeira, percebe-se que o indicador mais importante é a Cobertura de Juros, seguida pelo Retorno sobre o PL e pelo Perfil de Endividamento. Esses três indicadores de maior importância representam cerca de $60 \%$ da importância total da perspectiva financeira. Já na perspectiva operacional, observa-se que existe certo equilíbrio entre os indicadores, com uma leve vantagem para os indicadores de Margem Ebitda, FEC e DEC. Por fim, a análise da perspectiva socioambiental mostra que a Taxa de Comprometimento Ambiental e a Rentabilidade Agregada dos Investimentos são, respectivamente, os dois indicadores mais relevantes, respondendo juntos por quase $62 \%$ de toda importância da perspectiva socioambiental.

Palavras-chave: Desempenho Organizacional; Indicadores Financeiros; Indicadores Não Financeiros.

\begin{abstract}
This article aims to analyze the relevance of financial and nonfinancial ratios in the evaluation of organizational performance of companies in the Brazilian electricity distribution sector. In this regard, an exploratory study was conducted, using Delphi and Analytic Hierarchy Process (AHP) techniques. The results show that, in relation to the financial perspective, the most important indicator is the Interest Coverage, followed by Return on Equity and Debt Profile. Those three major ratios represent approximately $60 \%$ of the total importance of the financial perspective. In the operational perspective, a balance between the ratios is observed, with a slight advantage for the EBITDA margin, FEC e DEC ratios. Finally, the analysis of socioenvironmental perspective shows that the Environmental Commitment Rate and the Aggregate Profitability of Investments are, respectively, the two most important ratios, which, together represent approximately $62 \%$ of all social and environmental perspective importance.
\end{abstract}

Keywords: Organizational Performance; Financial Ratios; Non Financial Ratios. 


\section{INTRODUÇÃO}

A avaliação de desempenho organizacional é fundamental para se compreender se as ações e os resultados da empresa estão em sintonia com a estratégia estabelecida corporativamente (LAVIERI; CUNHA, 2009). Chaves, Alcântara e Assumpção (2008) complementam afirmando que a mensuração do desempenho é importante para verificar se os objetivos estabelecidos pela empresa estão sendo alcançados, ajudando ainda na melhor aplicação dos recursos.

Entretanto, existem muitas medidas para avaliar o desempenho das empresas, assim como diversas definições sobre desempenho organizacional. E sendo este um fenômeno complexo e multifacetado, acaba escapando de uma visão simplista. Diferentes pesquisadores têm focado sua atenção em aspectos distintos e específicos do conceito de desempenho (CARNEIRO et al., 2005).

A grande dificuldade atual é identificar qual a estrutura ideal do Sistema de Medição de Desempenho (SMD). De acordo com Silva, Pamplona e Bornia (2006), um SMD deve incluir medidas internas e externas à organização, financeiras e não financeiras, sem perder o foco estratégico. Entretanto, a questão central é inicialmente definir quais critérios devem ser observados e como eles devem ser combinados para que o resultado da avaliação seja satisfatório. Cabe ressaltar que os diferentes critérios podem ser agrupados em perspectivas de diferentes naturezas (CARNEIRO et al., 2005).

A questão da utilização de mais de uma perspectiva leva as organizações a abandonarem a avaliação de desempenho voltada somente para a área financeira, já que uma análise do desempenho organizacional por meio apenas de indicadores financeiros pode por vezes não refletir o real desempenho da organização (LUITZ e REBELATO, 2003).

De acordo com Miranda et al. (2003), enquanto a literatura tem mostrado que, no passado, as empresas tomavam decisões baseadas apenas em informações financeiras, obtidas da contabilidade das empresas, atualmente, a tomada de decisão envolve um maior número de variáveis, exigindo dos gestores uma grande preocupação com indicadores como: satisfação de clientes, qualidade dos produtos, participação no mercado, retenção de clientes, fidelidade dos clientes, inovação e habilidades estratégicas.

Além disso, por conta das empresas possuírem um compromisso com a sociedade e o meio ambiente, é necessário que exista um relacionamento de respeito na perspectiva social e também o interesse na preservação do meio ambiente, minimizando seus impactos. Assim, a empresa pode continuar a ser vista como um dos pilares fundamentais no desenvolvimento econômico e social (CASTRO, SIQUEIRA e MACEDO, 2010).

Assim sendo, essa pesquisa tem como objetivo analisar a relevância de indicadores financeiros e não financeiros na avaliação de desempenho organizacional de empresas do setor brasileiro de distribuição de energia elétrica.

Para tanto, será conduzido um estudo de caráter exploratório, com uso das técnicas Delphi e Análise Hierárquica (AHP), com o propósito de responder às seguintes questões, que compõem o problema de pesquisa: 
- Quais os indicadores financeiros e não financeiros mais importantes na avaliação de desempenho organizacional no setor brasileiro de energia elétrica?

- Dados esses indicadores, qual a relevância (peso) de cada um numa análise multicriterial de desempenho organizacional?

\section{REFERENCIAL TEÓRICO}

\subsection{Desempenho Organizacional com foco Financeiro e Não Financeiro}

Marr e Schiuma (2003) destacam que a medição de desempenho organizacional está no foco dos gestores de negócios e, de forma parecida, dos acadêmicos, e que esta tem necessariamente uma natureza multicriterial e multidisciplinar.

A mensuração de desempenho é definida por Neely (1998) como sendo o processo de quantificar a eficiência e a efetividade de ações passadas, através da aquisição, coleta, classificação, análise, interpretação e disseminação dos dados apropriados, gerando informações importantes para que ações preventivas e/ou corretivas sejam tomadas.

De acordo com Becker (2001), um bom sistema de mensuração deve ser capaz de orientar a empresa no processo de decisão, agilizando, consequentemente, o foco em atividades que realmente agreguem valor. Assim sendo, o desempenho está relacionado à forma como as estratégias e as metas são definidas pela organização e como elas orientam os esforços para garantir o sucesso organizacional.

Neely, Gregory e Platts (2005), declaram que um sistema de mensuração de performance pode ser definido como o jogo de métricas usado para quantificar tanto a eficiência quanto a eficácia das ações das empresas. Porém, os autores esclarecem que a mensuração do desempenho pode ser encarada como um processo de quantificação, mas seus efeitos são para estimular a ação, através de uma atuação gerencial consistente, que conduza à realização das estratégias.

Além disso, mensurar o desempenho organizacional é um processo permanente e repetitivo. Através de tal avaliação, além do melhoramento de falhas, o gestor pode se preparar para enfrentar as mudanças ambientais a que a empresa está sujeita, sendo interessante para a companhia realizar tal mensuração em relação a seu ambiente competitivo (MACEDO et al., 2008).

Entretanto, a etapa mais crítica é a determinação dos indicadores de desempenho a serem utilizados, pois esta define a eficiência do processo de medição. Segundo Chaves, Alcântara e Assumpção (2008) determinar quais as medidas que devem ser realizadas depende da complexidade do processo que se deseja avaliar, da sua importância em relação às metas estabelecidas pela empresa e da expectativa de uso gerencial posterior destes dados.

Existem diversos estudos sobre qual a melhor forma de avaliar o desempenho organizacional de uma empresa. Uma gama de definições para desempenho organizacional foi criada, mas não há um consenso sobre qual definição seria a melhor ou uma receita específica de critérios e indicadores a serem utilizados (BARNEY, 1996). Nesse contexto, um ponto a 
ser observado é o aumento da utilização de medidas não financeiras, que têm sido cada vez mais evidenciadas em decisões e relatórios. Não só pela necessidade que os executivos veem em ampliar suas ferramentas de gestão, mas também na propagação do uso dos sistemas de mensuração de desempenho demandada por essas necessidades. Dessa maneira, os indicadores não financeiros encontram um ambiente propício à sua implementação, sendo foco de várias metodologias e modelos de avaliação do desempenho organizacional, tal como o BSC Balanced Scorecard (VIANNA, 2009).

Hendriksen e Van Breda (1999) enfatizam que a mensuração do desempenho pode ser feita sob a ótica de valores monetários, normalmente utilizando dados contábil-financeiros, e/ou sob a ótica de informações não-monetárias. A conjugação de informações de ambas as naturezas pode levar o sistema de avaliação do desempenho a uma condição diferenciada no que diz respeito a certas predições para subsidiar o processo decisório.

De acordo com Netto (2007), ao longo da história pode-se observar a evolução da medição do desempenho direcionada para focos de interesse específico. Pode-se perceber que ao longo do tempo, tais sistemas de medição foram agregando às medidas puramente financeiras diversos atributos relacionados à gestão de pessoas, clientes, processos, recursos intangíveis e sustentabilidade.

Mesmo com a evolução de diversos sistemas de medição de desempenho, a dificuldade de se lidar com o universo de medidas de desempenho ainda é muito grande. Por ser um fenômeno que possui muitos aspectos, o desempenho organizacional acaba se tornando por muitas vezes complexo de se abordar (MACEDO e CORRAR, 2010).

Ainda segundo os autores, apesar da indiscutível importância dos aspectos não financeiros na análise e avaliação do desempenho organizacional, o que se observa é que ainda se tem na análise contábil-financeira o foco principal de muitos estudos. Assim sendo, o uso de medidas de desempenho financeiro ainda é o procedimento mais comum e sobre o qual existem inúmeros estudos comprovando sua eficiência. Esses índices possuem como principal fonte de informações as demonstrações financeiras.

De acordo com Souza (2005), os índices financeiros são inter-relações de contas das demonstrações financeiras, cada um fornecendo a visão de um tópico específico da situação ou desempenho da organização.

A avaliação de desempenho financeiro, quando bem realizada, garante suporte ao processo decisório na organização, principalmente quando são envolvidos planos estratégicos que podem influenciar no crescimento da organização e criação de valor para os acionistas. As análises com esse foco objetivam fundamentar o gestor no momento de definir políticas, ações e metas presentes no planejamento estratégico da organização (SOUZA, 2005). Além disso, a preocupação com índices financeiros é necessária também por conta da prestação de contas da empresa com a sociedade. Ou melhor, o desempenho financeiro influencia diretamente o comportamento social corporativo das empresas, pois as que têm um bom desempenho financeiro podem aplicar recursos na dimensão social (PAVIE, 2008).

Entretanto, apesar de muito importantes e essenciais para avaliar a saúde da empresa, os indicadores financeiros não são suficientes. Pois, apesar de servirem para avaliar a gestão e gerar algumas ações para que os objetivos sejam alcançados, são necessárias outras medidas de desempenho que consigam dar ao gestor maior segurança ao tomar suas decisões tanto interna 
quanto externamente à empresa (MACEDO e CORRAR, 2010).

Nesse sentido, o desempenho operacional é aquele que utiliza indicadores ligados à produtividade da empresa e à qualidade de seus produtos e serviços. Geralmente, estão vinculados à estrutura do âmbito (setor) ao qual a organização se insere (MACEDO et al., 2008).

Assim como as estratégias da empresa devem estar ligadas à criação de valor para os acionistas, elas também devem estar alinhadas ao planejamento e à execução dos processos (DIAS, 2008). Assim sendo, continua o autor, fatores como qualidade, flexibilidade, rapidez e confiabilidade são cada vez mais exigidos pelos clientes de uma empresa, causando um aumento de demanda pelo pacote de valores. Portanto, trabalhar os pontos de satisfação dos clientes tornou-se um dos fatores decisivos para o sucesso, sendo um forte aspecto na disputa pela competitividade no mercado.

Embora ainda pouco utilizados em análises, os quocientes socioambientais têm revelado sua importância ao longo do tempo. Tais índices são necessários para acompanhar o progresso nas diferentes dimensões socioambientais, tornando-se ferramentas de apoio aos tomadores de decisões e àqueles relacionados à elaboração de políticas, além de serem direcionadores para o alcance do desenvolvimento sustentável (GARCIA; GUERRERO, 2006).

Carneiro et al. (2005) ressaltam que incorporar a complexidade socioambiental ao mundo dos negócios é fundamental. São valores predominantes na sociedade que devem ser estendidos às instituições, ou seja, se uma empresa alcança bom desempenho financeiro à custa do meio ambiente ou da sociedade, seus objetivos não estarão sendo atingidos de maneira equilibrada e seu futuro pode ficar ameaçado por ações de governo ou por boicote de clientes. Além disso, conforme Noguti et al. (2008), a tendência mundial é que investidores procurem investir seus recursos em empresas que sejam ambientalmente sustentáveis e socialmente responsáveis, além de rentáveis. Essa tendência segue o conceito do Triple Botton Line (TBL), que considera de forma integrada os resultados empresariais nas dimensões econômico-financeira, social e ambiental.

Segundo Macedo, Corrar e Siqueira (2009), a amplidão do conceito de desempenho socioambiental associado à necessidade de manutenção da integridade financeira e operacional da empresa, pode levar a diferentes interpretações de como se dará a gestão das organizações. Nesse contexto, esse trabalho busca analisar a importância de uma série de indicadores de perspectivas distintas (financeira, operacional e socioambiental) na avaliação do desempenho organizacional.

\section{METODOLOGIA}

Esta pesquisa pode ser caracterizada, de acordo com Vergara (2009), como sendo descritiva e exploratória, pois objetiva, através da aplicação das técnicas Delphi e da Análise Hierárquica (AHP), analisar a relevância de indicadores financeiros e não financeiros para a avaliação de desempenho no setor de distribuição de energia elétrica no Brasil. 
A escolha por um estudo sobre o setor elétrico se justifica por sua relevância econômica e social. Segundo Bhattacharyya (2007), o papel fundamental que o setor de energia elétrica tem na atividade econômica fica por conta da mútua interdependência entre a economia e o setor elétrico. Isso porque o setor de energia utiliza insumos de vários setores produtivos e este setor também constitui insumo para outros diversos tipos de atividades econômicas. Por conta desse papel estratégico do setor, estudos sobre o desempenho de suas empresas se tornam pertinentes.

Além disso, no atual cenário, de regulamentação por parte do Estado e oferta/entrega de energia por parte das empresas, algumas privadas e outras ainda estatais, Blose e Tankersley (2004) comentam que tanto as organizações públicas quanto as privadas estão direcionadas no sentido da racionalização dos custos e da orientação de seus serviços para os clientes, visando à retenção dos mesmos. Algumas empresas estão ainda disponibilizando a chamada energia "ambientalmente" correta, gerada a partir de fontes não poluidoras.

Isso tudo mostra que o setor precisa ser foco permanente de processos de avaliação de desempenho, e que este processo precisa cada vez mais focar as perspectivas financeira, operacional e socioambiental.

O processo de amostragem é não probabilístico, pois parte de um universo naturalmente restrito, já que foram consultados os 20 analistas da área de Risco de Crédito do Banco de Desenvolvimento Econômico e Social - BNDES, que trabalham com o setor elétrico.

Os indicadores a serem analisados foram obtidos com base nos indicadores utilizados na análise do setor elétrico, publicada no Anuário Séries 2010, que é produzido pelo GESEL/ UFRJ. Tem-se, então, uma limitação importante, pois somente os indicadores utilizados por essa publicação foram analisados. Cabe ressaltar, entretanto, que o GESEL/UFRJ é um grupo de estudos do setor elétrico com mais de 10 anos de existência, que publica entre outros documentos o Anuário de Análise Econômica e Financeira das Empresas do Setor de Energia Elétrica - Séries, que em 2010 teve sua $11^{\text {a }}$ edição.

De posse de 38 indicadores divididos em três perspectivas: financeira, operacional e socioambiental, elaborou-se um questionário autopreenchível que tinha como objetivo que o respondente apontasse os indicadores mais relevantes. Os indicadores utilizados estão listados a seguir:

a) Perspectiva financeira (16 indicadores): Rotação do Ativo, Multiplicador de Alavancagem, Endividamento Total, Perfil do Endividamento, Endividamento Oneroso, Cobertura de Juros, Imobilização do Patrimônio Líquido, Imobilização dos Recursos não Correntes, Liquidez Corrente, Liquidez Imediata, Rentabilidade Financeira sobre o Patrimônio Líquido (RFPL), Retorno sobre o Patrimônio Líquido (RSPL), Necessidade de Investimento em Capital de Giro (NIG) sobre Receita Líquida, Necessidade Total de Financiamento Permanente (NTFP) sobre o Ativo, Saldo Disponível (SD) sobre a Receita Líquida e Capital de Giro (Circulante) Líquido sobre o Ativo;

b) Perspectiva Operacional (15 indicadores): Consumo Médio Mensal, Preço Médio (R\$/MWh), Cliente por Empregado, Despesa Financeira Unitária (R \$MWh), Perdas de Vendas, Geração Operacional de Caixa (EBIT), Margem Bruta ou Margem Ebit, Razão Operacional, Margem Ebitda, DEC, FEC, Rentabilidade Financeira sobre o Ativo Total (RFAT), Retorno sobre o Ativo (RSA), Rentabilidade Financeira sobre o Ativo Operacional (RFAO) e Taxa de recuperação de Caixa; 
c) Perspectiva Socioambiental (7 indicadores): Giro Social Interno (\%), Giro Social Externo (\%), Rentabilidade Agregada dos Investimentos, Retorno Social sobre a remuneração dos Empregados, Riqueza Gerada por Empregado, Taxa de Comprometimento Ambiental e Criação de Riqueza por unidade de receita.

Nota-se que essa listagem inclui indicadores financeiros e não financeiros, em suas diversas perspectivas. Para os grupos de indicadores financeiros e operacionais, os respondentes eram solicitados a escolher apenas oito indicadores como relevantes para uma análise de desempenho. Já para a perspectiva socioambiental o limite era de quatro indicadores. Vale ressaltar que para reduzir a limitação do estudo em relação à lista inicial de indicadores, o questionário apresentava uma última pergunta aberta sobre a indicação de outros indicadores não contemplados nas listagens apresentadas. Cabe ainda ressaltar que para evitar divergências de entendimento sobre cada indicador, foi apresentada ao respondente uma definição para o mesmo, bem como sua fórmula de cálculo.

Por fim, em relação ao questionário, destaca-se que antes da aplicação do mesmo aos analistas do BNDES, realizou-se um teste piloto com três professores da área de análise econômico-financeira, com a finalidade de testar a inteligibilidade do instrumento de coleta de dados (principalmente em relação a dúvidas de entendimento, dificuldade de interpretação e inconsistências dos quesitos). As observações feitas pelos respondentes desse teste piloto foram incorporadas ao questionário antes de sua aplicação.

A técnica Delphi foi utilizada para analisar as 15 respostas obtidas desse primeiro questionário. De acordo com Wright e Giovinazzo (2000), o Método Delphi originalmente tem o objetivo de buscar um consenso de opiniões de um grupo de especialistas a respeito de eventos futuros e tendências. A execução da técnica é simples. Numa primeira rodada, os respondentes recebem um questionário para responderem individualmente. Na próxima rodada, as respostas recebem um tratamento estatístico simples e em seguida são devolvidas aos participantes. A cada nova rodada o mesmo questionário é repassado e os participantes devem reavaliar suas respostas face às respostas dos demais respondentes da rodada anterior. O processo é repetido até que a divergência entre as respostas dos especialistas chegue a um nível satisfatório (WRIGHT; GIOVINAZZO, 2000).

Nessa pesquisa, a técnica Delphi foi aplicada em duas rodadas, pois observou-se que não haveria possibilidades de maior congruência entre os respondentes. Isso foi percebido pela baixa oscilação nas frequências dos indicadores: os mais importantes continuaram como mais importantes e os menos importantes continuaram como menos importantes, sem alterações significativas de frequência.

De posse destes indicadores escolhidos pelos respondentes, procedeu-se uma análise de correlação para verificar se existiam indicadores que pudessem representar uma mesma dimensão do desempenho organizacional.

O primeiro passo dessa análise foi verificar se os valores desses indicadores nas empresas do setor brasileiro de distribuição de energia elétrica, que constavam na base do GESEL Anuário Séries 2010, tinham distribuição normal. Isso se faz necessário para determinar qual medida de correlação pode ser utilizada (paramétrica ou não paramétrica).

Com base nos valores desses indicadores para as 42 empresas listadas no Anuário Séries 2010, aplicou-se o teste de normalidade de Kolmogorov-Smirnov, que compara a distribuição 
de frequência acumulada de um conjunto de valores da amostra com uma distribuição esperada, ou seja, testa se as variáveis em estudo possuem ou não uma distribuição normal (FÁVERO et al., 2009).

Verificou-se não haver normalidade para a maioria dos índices analisados, pois o p-valor foi inferior ao nível de significância $5 \%$, não sendo aceita, portanto, a $\mathrm{H}_{0}$ de que a distribuição dos indicadores tende a uma distribuição normal. Sendo assim, o coeficiente de correlação utilizado foi o de Spearman.

O coeficiente de Spearman, que é uma medida não paramétrica, mede a intensidade da relação entre variáveis no mínimo ordinais. Usa, em vez do valor observado, apenas a ordem das observações, sem fazer nenhuma suposição sobre a distribuição de frequência das variáveis. Deste modo, este coeficiente não é sensível a assimetrias na distribuição, nem à presença de outliers, não exigindo, portanto, que os dados provenham de populações normais (SIEGEL e CASTELLAN Jr., 2006).

Com o resultado do teste de correlação, foi obtida a lista de indicadores para a próxima etapa, que seria a análise do grau de importância (hierarquia) dos índices selecionados. Para essa análise da relevância (peso) de cada indicador na avaliação de desempenho organizacional, utilizou-se a Análise Hierárquica (AHP), que é um método multicritério de apoio à decisão (MCDA).

O Apoio Multicritério à Decisão (AMD) consiste, então, em um conjunto de métodos e técnicas para auxiliar ou apoiar a tomada de decisões, quando da presença de múltiplos critérios (GOMES, GONÇALEZ-ARAYA e CARIGNANO, 2004).

Dentre os métodos de Apoio Multicritério à Decisão (AMD) destaca-se a Análise Hierárquica (AHP - Analytic Hierarchy Process), que, segundo Gomes, Gonçalez-Araya e Carignano (2004), foi um dos primeiros métodos de análise multicritério, e deve ser um dos mais usados no mundo. Este vem sendo desenvolvido ao longo dos anos, podendo-se dizer que hoje ele integra uma família de métodos: Clássico, Multiplicativo, Referenciado e B-G.

A AHP é um dos métodos mais utilizados para tomada de decisões em análises multicriteriais, pois uma das principais vantagens deste método é a facilidade com que ele lida com vários critérios, possuindo a capacidade de analisar um problema considerando múltiplos objetivos. Além disso, por não envolver matemática complicada, a AHP é mais fácil de entender, podendo gerir eficazmente dados qualitativos e quantitativos (KAHRAMAN, CEBECI e ULUKAN, 2003).

De acordo com Anderson, Sweeney e Williams (2005) a AHP, desenvolvida por T. L. Saaty na década de 1970, exige que o decisor faça julgamentos acerca da importância relativa de cada critério e depois especifique a preferência por cada alternativa usando cada critério.

Isso é feito, de acordo com Gomes, Gonçalez-Araya e Carignano (2004), através de comparações, par a par, das alternativas e dos critérios, criando-se várias matrizes de decisão quadradas, onde à cada critério e à cada alternativa associa-se um valor de prioridade sobre as outras em análise, a partir de uma escala fundamental de preferências.

Ainda segundo Anderson, Sweeney e Williams (2005), a base da AHP é, portanto, a análise comparativa par a par, tanto dos critérios, quanto das alternativas, para definir preferências 
(hierarquizar). Para isso, continuam os autores, é necessário estabelecer, primeiramente, o quão importante cada critério ou cada alternativa é em relação a cada um dos outros. Isso é feito através da construção de uma matriz quadrada de decisão, onde os critérios ou alternativas podem ser comparados aos pares, seguindo a escala de comparação de Saaty. A seguir, no quadro 01, encontra-se a descrição desta escala.

Pode-se perceber, segundo Gomes, Gonçalez-Araya e Carignano (2004) e Anderson, Sweeney e Williams (2005), que a escala define apenas o que é mais importante e quão mais importante. No caso de, por exemplo, um critério i ter importância grande ou essencial em relação a j, será atribuído o valor 5 da escala para a comparação de i em relação a j (linha i e coluna j da matriz de decisão). Já na comparação de j em relação a i (linha j e coluna i da matriz de decisão) será atribuído o inverso deste valor, ou seja, 1/5. Ou seja, para o menos importante, a comparação assume o valor inverso ou recíproco da escala original.

De acordo com Anderson, Sweeney e Williams (2005) e Gomes, Gonçalez-Araya e Carignano (2004), para priorizar cada critério ou cada alternativa dentro de cada critério, a partir da matriz de comparação, é utilizado o método de sintetização das preferências da AHP.

Primeiramente, somam-se os valores de cada coluna da matriz de comparação par a par, depois uma nova matriz é construída dividindo-se cada valor da matriz original pelo somatório de sua coluna, ou seja, efetuando-se o que é denominado a normalização da matriz. Depois, calcula-se a média de cada linha da matriz normalizada. Tem-se, então, a priorização/ hierarquização dos critérios ou das alternativas frente a um determinado critério. Cabe ressaltar que a soma destes índices de priorização dos critérios ou das alternativas dentro de um critério deve ser igual a 1,00 (MACEDO e CORRAR, 2010).

\begin{tabular}{|c|c|c|}
\hline $\begin{array}{c}\text { Intensidade de } \\
\text { Importância }\end{array}$ & Definição & Explicação \\
\hline $\mathbf{1}$ & Mesma Importância & $\begin{array}{c}\text { As duas atividades contribuem igualmente } \\
\text { para o objetivo. }\end{array}$ \\
\hline $\mathbf{3}$ & Importância pequena de uma sobre a outra & $\begin{array}{c}\text { A experiência e o julgamento favorecem } \\
\text { levemente uma atividade em relação a outra. }\end{array}$ \\
\hline $\mathbf{5}$ & Importância grande ou essencial & $\begin{array}{c}\text { A experiência e o julgamento favorecem } \\
\text { fortemente uma atividade em relação a outra. }\end{array}$ \\
\hline $\mathbf{7}$ & $\begin{array}{c}\text { Importância muito grande ou demonstrada } \\
\text { favorecida em relação a outra; sua }\end{array}$ \\
\hline $\begin{array}{c}\text { Importância absoluta } \\
\text { dominação de importância é demonstrada na } \\
\text { prática. }\end{array}$
\end{tabular}

Quadro 1: Escala de Comparações de Saaty

Fonte: Saaty (1991) 
De acordo com Anderson, Sweeney e Williams (2005) e Costa (2002), para todas as matrizes de comparação (entre critérios e entre alternativas para cada critério) é necessário testar a consistência da análise e do modelo construído. Segundo Saaty (1991), o teste de consistência tem que ser de tal ordem que se possa testar ao mesmo tempo não só a violação de transitividade (A é preferível a B; B é preferível a $\mathrm{C}$; logo, $\mathrm{A}$ tem de ser preferível a $\mathrm{C}$ ), como também a de proporcionalidade (A é duas vezes preferível a B; B é três vezes preferível a C; logo, A tem de ser seis vezes preferível a $C$ ).

De acordo com Lyra (2008), no procedimento inicial da AHP, ocorre um processo de medidas e de julgamentos, concentrando-se nesta etapa a maioria das limitações auferidas ao modelo. Por serem julgamentos subjetivos, a técnica recebe algumas críticas na literatura. $\mathrm{Na}$ realidade, o ponto central não está no método, mas na inconsistência das pessoas, inconsistências essas que podem ocorrer por desconhecimento técnico, falta de experiência, envolvimento ou neutralidade no processo de julgamento. É por conta disso que se faz necessário testar as consistências das matrizes de comparação par a par.

Segundo Saaty (1991), para verificar a consistência da análise, são necessárias algumas operações entre matrizes. Primeiramente multiplica-se a matriz de comparação ( $\mathrm{n}$ x n) pelo vetor de pesos (resultado hierarquizado para os critérios, ou alternativas para cada critério, ou vetor de priorização dos critérios, ou alternativas). A partir daí, há um novo vetor. Divide-se a primeira componente deste vetor pela primeira componente do vetor de pesos, a segunda componente deste vetor pela segunda componente do vetor de pesos e assim por diante, até obter-se um novo vetor. A média dos elementos deste último vetor será o $\lambda_{\max }$. O quociente entre $\left(\lambda_{\max }-n\right)$ e (n -1) é o que Anderson, Sweeney e Williams (2005) denominam de índice de consistência (IC), que de acordo com Saaty (1991) tenderá a zero quanto mais consistente for o resultado.

Para analisar a consistência, de acordo com Gomes, Gonçalez-Araya e Carignano (2004), utiliza-se um indicador denominado razão de consistência (RC), que é obtido pela divisão do IC por um índice aleatório, calculado para matrizes quadradas de ordem $\mathrm{n}$ pelo Laboratório Nacional de Oak Ridge, nos EUA, denominado índice randômico (IR). Quando $n \geq 4$, o valor aceitável para a razão de consistência é $\mathrm{RC} \leq 0,10$.

Os valores do IR que serão considerados nesta análise, para matrizes quadradas, de acordo com Saaty (1991) são de: 0,90 para $n=4 ; 1,12$ para $n=5$ e 1,24 para $n=6$.

Em síntese, segundo Lyra (2008), o processo de utilização da AHP possui basicamente cinco etapas: (1) definir o problema e a estrutura hierárquica; (2) construir matrizes de prioridade; (3) obter as matrizes de prioridades relativas; (4) checar as consistências das matrizes; (5) decidir as prioridades.

Nesse estudo, utiliza-se a AHP para hierarquizar os indicadores dentro de cada perspectiva. Para tanto, os mesmos analistas do BNDES foram convidados a responder a um segundo questionário, onde fariam comparações de cada indicador (par a par) com todos os outros indicadores da mesma perspectiva. Assim, obtém-se para cada respondente em cada perspectiva uma matriz de comparação dos indicadores, de onde se observa o peso/importância de cada indicador dentro de cada perspectiva. Para consolidar uma única importância/peso para 
cada indicador procedeu-se a média das importâncias de cada respondente.

Para essa etapa obteve-se 12 questionários respondidos, sendo que apenas seis respostas para cada perspectiva foram consideradas válidas, dentro do limite de consistência estabelecido $(\mathrm{RC} \leq 0,10)$.

Cabe ressaltar que antes de ser aplicado aos analistas do BNDES, esse segundo questionário também passou por um pré-teste frente a alunos integrantes do curso de mestrado em Ciências Contábeis de uma instituição de ensino no Rio de Janeiro, também com o objetivo de testar a inteligibilidade do instrumento de coleta. Com base nos resultados, alguns ajustes foram realizados antes da aplicação do questionário aos respondentes.

\section{APRESENTAÇÃO E ANÁLISE DOS RESULTADOS}

Conforme mencionadona metodologia, a primeira fase dessa pesquisa foi a aplicação do questionário para verificar quais seriam os indicadores financeiros e não financeiros relevantes na avaliação de desempenho organizacional no setor de distribuição de energia elétrica no Brasil. Vale ressaltar que não foram indicados novos indicadores além dos 38 iniciais.

Pela aplicação da técnica Delphi, obteve-se a seguinte lista de indicadores mais importante em cada perspectiva (Tabela 1). Tem-se, então, listados pelos respondentes, sete indicadores financeiros (dos 16 iniciais), oito indicadores operacionais (dos 15 iniciais) e cinco indicadores socioambientais (dos sete iniciais). Num primeiro momento, com base na listagem inicial, podese concluir que esses são os indicadores financeiros e não financeiros mais importantes numa análise de desempenho organizacional no setor brasileiro de distribuição de energia elétrica.

Em cada perspectiva, o ponto de corte se deu próximo a $50 \%$ de frequência relativa para cada indicador. No caso da perspectiva financeira, o primeiro indicador fora da lista foi Multiplicador de Alavancagem com 33\% de frequência. Já para as perspectivas operacional e socioambiental, os primeiros indicadores fora da lista foram Margem Bruta/EBIT (20\%) e Riqueza Gerada por Empregado (27\%), respectivamente. Percebe-se, assim, que o ponto de corte denota uma mudança relativamente significativa na importância dos indicadores, pois os primeiros fora da lista estão a mais de $15 \%$ de diferença na frequência relativa.

Com base nesta listagem, procedeu-se uma análise de correlação entre os valores desses indicadores para as empresas distribuidoras de energia elétrica, que constavam no Anuário Séries 2010 do GESEL/UFRJ. Os resultados apontaram, primeiramente pelo teste de normalidade de Kolmogorov-Smirnov (Tabela 2), que a maioria das variáveis não apresentava tendência à distribuição normal ( $p$-valor $<0,05$ ). Logo, decidiu-se pela aplicação da correlação de Sperman, conforme já relatado na metodologia. 
Tabela 1: Indicadores Obtidos pela Técnica Delphi

\begin{tabular}{|c|c|c|}
\hline Indicadores Financeiros & $1^{\text {a }}$ Etapa & $2^{\text {a }}$ Etapa \\
\hline Cobertura de Juros & $100 \%$ & $100 \%$ \\
\hline Perfil do Endividamento & $87 \%$ & $87 \%$ \\
\hline $\begin{array}{l}\text { Necessidade de Investimento em Capital de Giro (NIG) / Receita } \\
\text { Líquida }\end{array}$ & $80 \%$ & $80 \%$ \\
\hline Endividamento Oneroso & $67 \%$ & $67 \%$ \\
\hline Necessidade Total de Financiamento Permanente (NTFP) / Ativo & $53 \%$ & $60 \%$ \\
\hline Retorno sobre o Patrimônio Líquido (RSPL) & $47 \%$ & $53 \%$ \\
\hline Endividamento Total & $53 \%$ & $47 \%$ \\
\hline Indicadores Operacionais & $\mathbf{1}^{\mathrm{a}}$ Etapa & $2^{\text {a }}$ Etapa \\
\hline Perdas de Vendas & $100 \%$ & $100 \%$ \\
\hline $\mathrm{DEC}$ & $100 \%$ & $100 \%$ \\
\hline Margem Ebitda & $87 \%$ & $87 \%$ \\
\hline FEC & $80 \%$ & $87 \%$ \\
\hline Preço Médio (R\$/MWh) & $80 \%$ & $80 \%$ \\
\hline Retorno sobre o Ativo (RSA) & $53 \%$ & $60 \%$ \\
\hline Consumo Médio Mensal & $53 \%$ & $53 \%$ \\
\hline Geração Operacional de Caixa (EBIT) & $53 \%$ & $53 \%$ \\
\hline Indicadores Socioambientais & $1^{\text {a }}$ Etapa & $2^{\text {a }}$ Etapa \\
\hline Taxa de Comprometimento Ambiental & $87 \%$ & $87 \%$ \\
\hline Giro Social Externo (\%) & $67 \%$ & $67 \%$ \\
\hline Giro Social Interno (\%) & $47 \%$ & $60 \%$ \\
\hline Rentabilidade Agregada dos Investimentos & $53 \%$ & $53 \%$ \\
\hline Retorno Social s/ a remuneração dos Empregados & $47 \%$ & $47 \%$ \\
\hline
\end{tabular}

Tabela 2: Resultado do Teste de Normalidade (Kolmogorov-Smirnov)

\begin{tabular}{|l|c|l|c|}
\hline Indicadores & p-valor & Indicadores & p-valor \\
\hline Cobertura de Juros & 0,0000 & Margem Ebitda & 0,0000 \\
\hline Perfil do Endividamento & 0,2000 & Retorno s Ativo & 0,0430 \\
\hline NIG/RL & 0,0000 & Preço Médio & 0,2000 \\
\hline Endividamento Oneroso & 0,0000 & Consumo Médio & 0,0040 \\
\hline NTFP/Ativo & 0,0020 & EBIT & 0,0010 \\
\hline Retorno s PL & 0,0060 & Giro Social Interno & 0,0340 \\
\hline Endividamento Total & 0,0070 & Giro Social Externo & 0,2000 \\
\hline Perdas Vendas & 0,0022 & Taxa Compromet. Ambiental & 0,0000 \\
\hline DEC & 0,0000 & Rentabil. Agreg. dos Invest. & 0,2000 \\
\hline FEC & 0,0000 & Ret. Soc. Rem. Empregado & 0,0320 \\
\hline
\end{tabular}

O teste de correlação (Spearman) aplicado aos indicadores teve como objetivo verificar se existiam indicadores correlacionados que poderiam estar sinalizando uma mesma dimensão da análise de desempenho multicriterial. Os resultados revelaram que, na dimensão financeira, o indicador que mede o Endividamento Total estava altamente correlacionado com o Endividamento Oneroso $(0,590$ e p-valor $=0,000)$ e a Necessidade de Investimento em Capital de Giro em relação à Receita Líquida $(-0,469$ e p-valor $=0,002)$, sendo descartado da lista de índices financeiros. 
Já na perspectiva operacional, foram retirados da listagem de indicadores os índices de Perdas de Vendas e o EBIT. O primeiro, por estar altamente correlacionado com outros quatro indicadores: $\operatorname{DEC}(0,672$ e p-valor $=0,000)$, FEC (0,581 e p-valor $=0,000)$, Preço Médio $(0,690$ e p-valor $=0,000)$ e Consumo Mensal $(-0,491$ e p-valor $=0,002)$; e o segundo, por estar correlacionado com outros três indicadores: FEC $(-0,418$ e p-valor $=0,006)$, Margem Ebitda $(0,540$ e p-valor $=0,000)$ e Retorno sobre o Ativo $(0,559$ e p-valor $=0,000)$. Uma observação importante é o fato do DEC e do FEC estarem altamente correlacionados $(0,791$ e $\mathrm{p}$-valor $=0,000)$, entretanto, os dois indicam medidas totalmente diferentes, justificando a sua continuação na análise.

Ainda na dimensão operacional, decidiu-se pela consolidação de dois indicadores: Preço Médio e Consumo Mensal. Dessa forma, tem-se um indicador único que mede o Custo Médio por Cliente. Essa consolidação foi realizada com base em algumas observações feitas pelos respondentes na etapa Delphi, que identificaram que estes indicadores se complementam e que a análise em separado não faria sentido.

Já na perspectiva socioambiental, o indicador desconsiderado foi o Retorno Social sobre a Remuneração dos Empregados, que estava correlacionado com o Giro Social Interno $(0,702$ e p-valor $=0,000)$ e o Giro Social Externo $(-0,312$ e p-valor $=0,047)$. Os demais indicadores não demonstraram nenhuma correlação significativa entre eles.

Assim sendo, restaram 15 indicadores dos 20 selecionados pela técnica Delphi: seis indicadores financeiros, cinco indicadores operacionais e quatro indicadores socioambientais, que se encontram listados na Tabela 3 (e descritos com detalhes no anexo), para a análise da relevância pela aplicação da AHP.

Conforme mencionado anteriormente na metodologia, o segundo questionário contou com 12 respondentes. De cada um dos respondentes foram obtidas três matrizes de comparação dos indicadores par a par, sendo uma para cada perspectiva. Assim sendo, procedeu-se a 36 testes de consistência, um para cada matriz de comparação. Esses testes mostraram que 18 matrizes de comparação não poderiam ser consideradas, pois violavam a consistência mínima exigida $(\mathrm{RC} \leq 0,10)$. Isso mostra que vários analistas não são capazes de fazer comparações consistentes entre os indicadores, no que diz respeito a sua importância.

Para análise com uso da AHP, sobraram então 18 matrizes de comparação dos indicadores, sendo seis para cada perspectiva. Na Tabela 3 são mostrados os pesos atribuídos por cada respondente válido (com RC dentro do limite) a cada indicador, bem como a importância média.

Em relação à perspectiva financeira, pode-se perceber que o indicador mais importante é a Cobertura de Juros, seguida pelo Retorno sobre o PL e pelo Perfil de Endividamento. Esses três indicadores de maior importância respondem por cerca de $60 \%$ da importância total da perspectiva financeira. Isso pode estar sendo influenciado pelo perfil dos respondentes, que são analistas de um banco de investimento, que têm como objetivo fazer financiamentos de longo prazo. Logo, a questão do endividamento e do retorno são os itens mais relevantes. Além disso, percebe-se que os indicadores relacionados ao endividamento correspondem a mais de $50 \%$, deixando para a rentabilidade e a questão do capital de giro e investimentos fixos os outros $50 \%$.

Já na perspectiva operacional, observa-se certo equilíbrio entre os indicadores, como uma leve vantagem para os indicadores de Margem Ebitda, FEC e DEC, que são os três primeiros, respectivamente. É interessante ver como a questão da qualidade dos serviços, mensurada pelo 
FEC e DEC são relevantes, visto que as duas juntas somam quase 45\% da importância da perspectiva.

Por fim, a análise da perspectiva socioambiental mostra que a Taxa de Comprometimento Ambiental e a Rentabilidade Agregada dos Investimentos são, respectivamente, os dois indicadores mais relevantes, respondendo juntos por quase $62 \%$ de toda a importância da perspectiva socioambiental. É interessante notar que esses indicadores provêm de relatórios diferentes. O primeiro é proveniente de algum Relatório Social, enquanto o segundo da Demonstração do Valor Adicionado (DVA), que passou a ser obrigatória apenas a partir do exercício de 2008. Cabe salientar que no caso da questão ambiental, o setor elétrico segue o Modelo IBASE, por imposição da ANEEL (agência reguladora do setor elétrico).

Tabela 3: Importância (peso) de cada Indicador em cada Perspectiva

\begin{tabular}{|l|c|c|c|c|c|c|c|}
\hline Indicadores Financeiros & $\mathbf{1}$ & $\mathbf{2}$ & 3 & 4 & 5 & 6 & Média \\
\hline Cobertura de Juros & 0,2081 & 0,377 & 0,1268 & 0,4232 & 0,1497 & 0,2115 & 0,2494 \\
\hline Perfil do Endividamento & 0,5068 & 0,1191 & 0,0508 & 0,2218 & 0,0445 & 0,0813 & 0,1707 \\
\hline $\begin{array}{l}\text { Necessidade de Investimento em Capital } \\
\text { de Giro (NIG) / Receita Líquida }\end{array}$ & 0,0471 & 0,0432 & 0,1978 & 0,0926 & 0,1324 & 0,3846 & 0,1496 \\
\hline Endividamento Oneroso & 0,0986 & 0,1051 & 0,0383 & 0,1769 & 0,0611 & 0,0702 & 0,0917 \\
\hline $\begin{array}{l}\text { Necessidade Total de Financiamento } \\
\text { Permanente (NTFP) / Ativo }\end{array}$ & 0,0439 & 0,2709 & 0,211 & 0,0564 & 0,0421 & 0,2157 & 0,1400 \\
\hline Retorno sobre o Patrimônio Líquido (RSPL) & 0,0955 & 0,0846 & 0,3753 & 0,029 & 0,5702 & 0,0367 & 0,1986 \\
\hline Indicadores Operacionais & & & & & & & \\
\hline DEC & 0,3413 & 0,0653 & 0,1695 & 0,4461 & 0,1923 & 0,0878 & 0,2171 \\
\hline Margem Ebitda & 0,1897 & 0,1494 & 0,6319 & 0,0617 & 0,1495 & 0,3636 & 0,2576 \\
\hline FEC & 0,3413 & 0,1024 & 0,1103 & 0,2992 & 0,4192 & 0,1179 & 0,2317 \\
\hline Custo médio por cliente & 0,0439 & 0,2701 & 0,0447 & 0,1608 & 0,207 & 0,0594 & 0,1310 \\
\hline Retorno sobre o Ativo (RSA) & 0,0785 & 0,4129 & 0,0437 & 0,0322 & 0,032 & 0,3712 & 0,1618 \\
\hline $\begin{array}{l}\text { Indicadores Socioambientais } \\
\text { Taxa de Comprometimento Ambiental }\end{array}$ & 0,3725 & 0,0704 & 0,5505 & 0,067 & 0,4813 & 0,4592 & 0,3335 \\
\hline Giro Social Externo (\%) & 0,1341 & 0,2183 & 0,2351 & 0,4909 & 0,0979 & 0,3156 & 0,2487 \\
\hline $\begin{array}{l}\text { Rentabilidade Agregada } \\
\text { dos Investimentos }\end{array}$ & 0,4261 & 0,5716 & 0,0976 & 0,2913 & 0,2104 & 0,1163 & 0,2856 \\
\hline Giro Social Interno (\%) & 0,0674 & 0,1397 & 0,1168 & 0,1507 & 0,2104 & 0,1089 & 0,1323 \\
\cline { 1 - 5 }
\end{tabular}

\section{CONSIDERAÇÕES FINAIS}

Essa pesquisa teve como objetivo analisar a relevância de indicadores financeiros e não financeiros na avaliação de desempenho organizacional no setor brasileiro de distribuição de energia elétrica.

Para alcançar esse objetivo, foram utilizados dois questionários aplicados aos analistas da área de Risco de Crédito do Banco de Desenvolvimento Econômico e Social - BNDES, que trabalham com o setor elétrico.

Para a análise, foram utilizadas as técnicas Delphi e AHP. A Delphi utilizada no 
primeiro questionário teve como foco a convergência das opiniões dos analistas com relação aos indicadores relevantes. De posse da lista dos indicadores relevantes, aplicou-se o segundo questionário, com o objetivo de hierarquizá-los. Para isso, utilizou-se a AHP que forneceu os pesos/importância de cada indicador.

Os resultados mostraram que em relação à perspectiva financeira, pode-se perceber que o indicador mais importante é a Cobertura de Juros, seguida pelo Retorno sobre o PL e pelo Perfil de Endividamento. Esses três indicadores de maior importância respondem por aproximadamente $62 \%$ da importância total da perspectiva financeira.

Já na perspectiva operacional, observa-se certo equilíbrio entre os indicadores, como uma leve vantagem para os indicadores de Margem Ebitda, FEC e DEC, que são os três mais importantes. Por fim, a análise da perspectiva socioambiental mostra que a Taxa de Comprometimento Ambiental e a Rentabilidade Agregada dos Investimentos são, respectivamente, os dois indicadores mais relevantes, respondendo juntos por quase $62 \%$ de toda importância da perspectiva socioambiental.

Percebe-se que, apesar da grande importância atribuída a itens como DEC, FEC e Comprometimento Ambiental, os indicadores calculados a partir de informações advindas das demonstrações financeiras ainda apresentam grande importância para a mensuração do desempenho organizacional, quando observado pela ótica de analistas de um banco de desenvolvimento. Isso pode ser constatado pela grande importância de medidas como Margem Ebitda na perspectiva operacional e Rentabilidade Agregada dos Investimentos, provenientes da DRE e da DVA/BP, respectivamente.

Isso pode estar refletindo uma característica do setor, a de se estruturar como uma espécie de monopólio natural, pois, apesar da concorrência no mercado de empresas (Fusões e Aquisições) não se pode vislumbrar neste setor uma competitividade ao nível da prestação de serviço, visto que não há, de maneira geral, possibilidade de escolha de distribuidor de energia por parte dos consumidores. Assim, o foco no desempenho financeiro é reforçado, em detrimento de uma visão mais multicriterial para a performance organizacional.

Para futuros trabalhos, propõe-se a utilização dos indicadores aqui selecionados, bem como de seus pesos, numa avaliação de desempenho no setor de distribuição de energia elétrica no Brasil. E, além disso, como esse é um tema muito relevante para estudos de desempenho organizacional, a aplicação da metodologia proposta nesse estudo para verificar a relevância de indicadores financeiros e não financeiros em outros setores econômicos.

\section{REFERÊNCIAS}

ANDERSON, D. R.; SWEENEY, D. J.; WILLIAMS, T. A. An Introduction to Management Science: quantitative approaches to decision making. $11 \mathrm{ed}$. Ohio: Thomson/South-Western College, 2005.

BARNEY, J. B. Gaining and Sustaining Competitive Advantage. MA: Addison-Wesley Publishing Company, 1996. 
BECKER, B. E. Gestão estratégica de pessoas com "scorecard: interligando pessoas, estratégia e performance. Rio de Janeiro: Campus, 2001.

BHATTACHARYYA, S. C. Energy sector management issues: an overview. International Journal of Energy Sector Management, v.1, n.1, 2007.

BLOSE, J. E.; TANKERSLEY, W. B. Linking dimensions of service quality to organizational outcomes. Managing Service Quality. v. 14, n. 1, p. 75-89, 2004.

CARNEIRO, J. M. T.; SILVA, J. F.; ROCHA, A.; HEMAIS, C. A. Mensuração do Desempenho Organizacional: Questões Conceituais e Metodológicas. In: ENCONTRO DE ESTUDOS EM ESTRATÉGIA, 2, 2005, Rio de Janeiro. Anais do II 3Es. Rio de Janeiro: ANPAD, 2005. CDROOM.

CASTRO, F. A. R.; SIQUEIRA, J. R. M.; MACEDO, M. A. S. Análise da Utilização dos Indicadores Essenciais da Versão "G3", da Global Reporting Initiative, nos Relatórios de Sustentabilidade das Empresas do Setor de Energia Elétrica Sul Americano. Revista de Informação Contábil, v. 4, n. 4, p. 83-102, 2010.

CHAVES, G. L. D.; ALCÂNTARA, R. L. C.; ASSUMPÇAO, M. R. P. Medidas de Desempenho na Logística Reversa: o caso de uma empresa do setor de bebidas. Relatórios de Pesquisa em Engenharia de Produção da UFF, v. 8, art. 2, 2008.

COSTA, H. G. Introdução ao Método de Análise Hierárquica: análise multicritério no auxílio à decisão. Niterói: UFF, 2002.

DIAS, T. F. Avaliação de Indicadores Operacionais: Estudo de Caso de uma Empresa do Setor Ferroviário. 2008. 43f. Monografia. (Graduaçao em Engenharia de Produçao). Universidade Federal de Juiz de Fora. Juiz de Fora - MG, 2008.

FÁVERO, L. P.; BELFIORE, P.; SILVA, F. L. da; CHAN, B. L. Análise de dados-modelagem multivariada para tomada de decisões. Rio de Janeiro: Campus/Elsevier, 2009.

GARCIA, S.; GUERRERO, M. Indicadores de sustentabilidad ambiental em La gestión de espacios verdes: Parque urbano Monte Calvário, Tandil, Argentina. Rev. Geogr. Norte Gd., n.35, p.45-57, 2006.

GOMES, L. F. A. M.; GONZALEZ-ARAYA, M. C.; CARIGNANO, C. Tomada de decisões em cenários complexos. Rio de Janeiro: Pioneira Thompson Learning. 2004.

HENDRIKSEN, E. S.; VAN BREDA, M. F. Teoria da Contabilidade. São Paulo: Atlas, 1999.

KAHRAMAN, C.; CEBECI, U; ULUKAN, Z. Multi-criteria supplier selection using fuzzy AHP. Logistics Information Management, v. 16, n. 6, p. 382-394, 2003.

LAVIERI, C. A.; CUNHA, J. A. C. A Utilização da Avaliação de Desempenho Organizacional em Franquias. In: ENCONTRO NACIONAL DA ANPAD, 33, 2009, São Paulo. Anais do XXXIII EnANPAD. São Paulo: ANPAD, 2009. CD-ROOM.

LUITZ, M. P.; REBELATO, M. G. Avaliação do Desempenho Organizacional. In: ENCONTRO NAC. DE ENG. DE PRODUÇÃO, 23, 2003, Ouro Preto. Anais do XXIII ENEGEP. Ouro 
Preto-MG: ENEGEP, 2003. CD-ROOM.

LYRA, R. L. C. Análise Hierárquica dos Indicadores Contábeis sob a Ótica do Desempenho Empresarial. 2008. 161 f. Tese (Doutorado em Controladoria e Contabilidade) - Departamento de Contabilidade e Atuária, Faculdade de Economia, Administração e Contabilidade, Universidade de São Paulo, São Paulo.

MACEDO, M. A. S.; CORRAR, L. J. Análise do Desempenho Contábil-Financeiro de Seguradoras no Brasil no ano de 2007: um estudo apoiado em Análise Hierárquica (AHP). Contabilidade Vista \& Revista, v. 21, n. 3, p. 135-165, 2010.

MACEDO, M. A. S.; CORRAR, L. J.; SIQUEIRA, J. R. M. Análise Comparativa do Desempenho Contábil-Financeiro de Empresas Sócio-Ambientalmente Responsáveis no Brasil. In: CONGRESSO DA ANPCONT, 3, 2009, São Paulo. Anais do III Congresso da ANPCONT. São Paulo: ANPCONT, 2009. CD-ROOM.

MACEDO, M. A. S.; CÍPOLA, F. C.; FERREIRA, A. F. R.; SOUZA, M. F. A. Desempenhos Sócio-Ambiental, Operacional e Contábil-Financeiro no Setor Elétrico Brasileiro: aplicando DEA na análise da sustentabilidade multidimensional. In: ENCONTRO DA ASSOCIAÇÃO NACIONAL DE PÓS GRADUAÇÃO E PESQUISA EM ADMINISTRAÇÃO, 32, 2008, Rio de Janeiro. Anais do XXXII ENANPAD. Rio de Janeiro: ANPAD, 2008. CD-ROOM.

MARR, B.; SCHIUMA, G. Business Performance Measurement - past, present and future. Management Decision, v. 41, n. 8, p. 608-687, 2003.

MIRANDA, L. C.; MEIRA, J. M.; WANDERLEY, C. A.; SILVA, A. C. M. Indicadores de Desempenho Empresarial divulgados por empresas Norte Americanas. Contabilidade Vista e Revista, v.14, n. 2, p. 85-103, 2003.

NEELY, A. Measuring business performance. London: The Economist Books, 1998.

NEELY, A.; GREGORY, M.; PLATTS, K. Performance measurement system design - A literature review and research agenda. Internacional Journal of operations \& Production Management, v. 25, n. 12, p. 1226-1263, 2005.

NETTO, F. S. Medição de Desempenho Organizacional: um estudo das vantagens e desvantagens dos principais sistemas sob as óticas teórico-acadêmica e de práticas de mercado. In: ENCONTRO NACIONAL DAANPAD, 31, 2007, Rio de Janeiro. Anais do XXXI EnANPAD. Rio de Janeiro: ANPAD, 2007. CD-ROM.

NOGUTI, M. B.; CAMPOS, S. V. B.; RODRIGUES, T. M.; PUlling, T.; DiAS, J. de C. Sistema de Gestão ambiental - Natura cosméticos S/A. In: CONGRESSO NACIONAL DE EXCELÊNCIA EM GESTÃO, 4., 2008, Niterói, RJ. Anais do IV CNEG. Niterói, RJ: LATEC/ UFF, 2008. CD-ROM

PAVIE, J. J. E. Responsabilidade social corporativa e desempenho financeiro: uma metaanálise. 2008. 76 f. Dissertaçao. (Mestrado profissionalizante em Administraçao). Faculdade de Economia e Finanças IBMEC. Rio de Janeiro, 2008.

SAATY, T. L. Método de Análise Hierárquica. São Paulo: McGraw-Hill/Makron, 1991. 
SIEGEL, S.; CASTELlAN Jr., N. J. Estatística Não-Paramétrica para Ciências do Comportamento. 2 ed. Porto Alegre: Artmed, 2006.

SILVA, E. R. S.; PAMPLONA, E. O.; BORNIA, A. C. Contribuição dos Sistemas de Medição de Desempenho no Ambiente de Integração da Cadeia de Suprimentos. In: CONGRESSO BRASILEIRO DE CUSTOS, 13, 2006, Belo Horizonte. Anais do XIII CBC. Belo Horizonte: ABCustos, 2006. CD-ROOM.

SOUZA, A. A. Principais Ferramentas de Medição de Desempenho Econômico- Financeiro das Organizações. 2005. Disponível em: <http://www.administradores.com.br/>. Acesso em: 12 fev. 2011.

VERGARA, S. C. Projetos e Relatórios de Pesquisa em Administração. 10. ed. São Paulo: Atlas, 2009.

VIANNA, D. S. C. O balanced scorecard e o desempenho financeiro : uma análise relacional do setor elétrico brasileiro. 2009. 107 f. Dissertaçao. (Mestrado em Ciências Contábeis). Universidade Federal do Rio de Janeiro. Rio de Janeiro, 2009.

WRIGHT, J. T. C.; GIOVINAZZO, R. A. Delphi - Uma Ferramenta de Apoio ao Planejamento Prospectivo. Caderno de Pesquisas em Administraçao, v. 12, art. 5, 2000. 
ANEXO - Lista Final dos Indicadores Analisados

\begin{tabular}{|c|c|c|}
\hline $\begin{array}{l}\text { Indicadores } \\
\text { Financeiros }\end{array}$ & Fórmula & Significado \\
\hline Cobertura de Juros & $\begin{array}{l}\text { EBIT / (Despesas } \\
\text { Financeiras } \\
\text { Brutas) }\end{array}$ & $\begin{array}{l}\text { Avalia a capacidade da empresa de gerar recursos para fazer frente aos } \\
\text { encargos de sua dívida. Quanto mais elevado, maior o retorno proporcionado } \\
\text { por fontes onerosas. }\end{array}$ \\
\hline $\begin{array}{l}\text { Perfil do } \\
\text { Endividamento }\end{array}$ & $\mathrm{PC} /(\mathrm{PC}+\mathrm{PELP})$ & $\begin{array}{l}\text { Qual o percentual de obrigações }(\mathrm{CP}) \text { em relação às obrigações totais. Quanto } \\
\text { maior seu valor, mais concentrada a dívida no CP. }\end{array}$ \\
\hline $\begin{array}{l}\text { Necessidade de } \\
\text { Investimento em } \\
\text { Capital de Giro } \\
\text { (NIG) / Receita } \\
\text { Líquida }\end{array}$ & $\begin{array}{l}\text { (PC Operacional - } \\
\text { AC Operacional / } \\
\text { Receita Líquida }\end{array}$ & $\begin{array}{l}\text { Demonstra a parcela que a necessidade de investimento em giro da empresa } \\
\text { representa da Receita Líquida de Vendas. Quanto mais baixo seu valor, menor } \\
\text { a Necessidade de Financiamentos Operacionais. }\end{array}$ \\
\hline $\begin{array}{l}\text { Endividamento } \\
\text { Oneroso }\end{array}$ & $\begin{array}{l}\text { Emprést. Financ. } \\
\text { e Debêntures (CP } \\
\text { e LP) / PL }\end{array}$ & $\begin{array}{l}\text { Mede o percentual de capital próprio comprometido com os passivos que } \\
\text { geram explicitamente juros e encargos financeiros. Quanto maior seu valor, } \\
\text { mais elevada a dependência por fontes onerosas. }\end{array}$ \\
\hline $\begin{array}{l}\text { Necessidade Total } \\
\text { de Financiamento } \\
\text { Permanente (NTFP) } \\
\text { / Ativo }\end{array}$ & $\begin{array}{l}\text { (ARLP-Part. } \\
\text { - Recebíveis } \\
\text { Mútuos + Imob. + } \\
\text { Intang. + NIG) / } \\
\text { Ativo }\end{array}$ & $\begin{array}{l}\text { Mede o quanto do Ativo Total corresponde a Ativos Operacionais de CP e LP, } \\
\text { necessários à manutenção do nível atual de Atividade. Quanto mais elevado, } \\
\text { maior a necessidade de investimento das operações. }\end{array}$ \\
\hline $\begin{array}{l}\text { Retorno sobre o } \\
\text { Patrimônio Líquido } \\
\text { (RSPL) }\end{array}$ & $\begin{array}{l}\text { Lucro do Período } \\
\text { / PL }\end{array}$ & $\begin{array}{l}\text { Mede a remuneração (em termos de lucro) dos acionistas obtida pela empresa } \\
\text { em relação ao investimento próprio. Quanto mais alto seu valor, maior a } \\
\text { eficiência da empresa. }\end{array}$ \\
\hline $\begin{array}{l}\text { Indicadores } \\
\text { Operacionais }\end{array}$ & Fórmula & Significado \\
\hline DEC & & $\begin{array}{l}\text { Mede a duração de interrupção equivalente por consumidor, medida pelo } \\
\text { número de horas que, em média, cada consumidor ficou desligado no período. } \\
\mathrm{i}=\mathrm{n}^{\circ} \text { de interrupções; } \mathrm{T}(\mathrm{i})=\text { tempo de duração das interrupções (hora); Ca(i)= } \\
n^{\circ} \text { de consumidores atingidos nas interrupçôes; } \mathrm{Cs}=\mathrm{n}^{\circ} \text { total de consumidores. }\end{array}$ \\
\hline Margem Ebitda & $\begin{array}{l}\text { EBITDA / Receita } \\
\text { Líquida }\end{array}$ & $\begin{array}{l}\text { Mede o percentual do potencial de geração de caixa que a empresa produz para } \\
\text { cada unidade de vendas (não inclui despesas de depreciação, amortização e } \\
\text { exaustão). Quanto maior, melhor é a geração de caixa potencial por unidade de } \\
\text { vendas. }\end{array}$ \\
\hline FEC & & $\begin{array}{l}\text { Mede o número de interrupções ocorridas, em média, em cada unidade } \\
\text { consumidora, onde } \mathrm{i}=\mathrm{n}^{\circ} \text { de interrupções; } \mathrm{Ca}(\mathrm{i})=\mathrm{n}^{\mathrm{o}} \text { de consumidores } \\
\text { atingidos nas interrupções; } \mathrm{Cs}=\mathrm{n}^{\circ} \text { total de consumidores. }\end{array}$ \\
\hline $\begin{array}{l}\text { Custo Médio por } \\
\text { Cliente }\end{array}$ & \begin{tabular}{|l|} 
Consumo Médio \\
[Consumo (MWh) \\
$/ \mathrm{n}^{\circ}$ de clientes] \\
$\mathrm{x}$ Preço Médio \\
{$[\mathrm{CMV} / \mathrm{MWh}$} \\
distribuído]
\end{tabular} & Mede o custo médio de quanto é consumido por cliente. \\
\hline $\begin{array}{l}\text { Retorno sobre o } \\
\text { Ativo (RSA) }\end{array}$ & $\begin{array}{l}\text { EBIT / Ativo } \\
\text { Operacional }\end{array}$ & $\begin{array}{l}\text { O quanto do investimento operacional da empresa gerou em termos de lucro } \\
\text { da atividade. Ativo Operac.: Ativo exceto disponib., participações e valor } \\
\text { a receber. Quanto maior seu valor, melhor a eficiência no uso dos Ativos } \\
\text { Operacionais. }\end{array}$ \\
\hline $\begin{array}{c}\text { Indicadores } \\
\text { Socioambientais }\end{array}$ & Fórmula & Significado \\
\hline $\begin{array}{l}\text { Taxa de } \\
\text { Comprometimento } \\
\text { Ambiental }\end{array}$ & $\begin{array}{l}\text { Investimento meio } \\
\text { ambiente / RL }\end{array}$ & $\begin{array}{l}\text { Mede os investimentos na área ambiental em relação à Receita Líquida. Ou } \\
\text { seja, o quanto da Receita Líquida está comprometida com gastos ambientais. }\end{array}$ \\
\hline $\begin{array}{l}\text { Giro Social Interno } \\
(\%)\end{array}$ & $\begin{array}{l}\text { Indicador Social } \\
\text { Interno / RL }\end{array}$ & $\begin{array}{l}\text { Mede o total de recursos investidos no bem-estar dos funcionários em relação } \\
\text { à Rec. Líq. Quanto maior, melhor. }\end{array}$ \\
\hline $\begin{array}{l}\text { Rentabilidade } \\
\text { Agregada dos } \\
\text { Investimentos }\end{array}$ & $\begin{array}{l}\text { Valor Adicionado } \\
\text { a Distribuir /Ativo }\end{array}$ & $\begin{array}{l}\text { Mede o percentual de riqueza líquida obtida pela empresa em relação ao ativo } \\
\text { da empresa. Quanto maior melhor. }\end{array}$ \\
\hline $\begin{array}{l}\text { Giro Social Externo } \\
(\%)\end{array}$ & $\begin{array}{l}\text { Indicador Social } \\
\text { Externo / RL }\end{array}$ & $\begin{array}{l}\text { Indica o percentual de todos os recursos investidos pelas empresas em } \\
\text { benefício da sociedade em relação à Receita Líquida. Quanto maior, melhor. }\end{array}$ \\
\hline
\end{tabular}




\section{DADOS DOS AUTORES:}

\section{MAITÊ GARCIA CRUZ RIBEIRO}

Universidade Federal do Rio de Janeiro

FACC - Faculdade de Administração e Ciências Contábeis.

Av. Pasteur, 250 - Depto de Contabilidade/FACC/UFRJ - Urca

22290-240 - Seropedica, RJ - Brasil

\section{MARCELO ÁLVARO DA SILVA MACEDO}

Universidade Federal do Rio de Janeiro

FACC - Faculdade de Administração e Ciências Contábeis.

Av. Pasteur, 250 - Depto de Contabilidade/FACC/UFRJ - Urca

22290-240 - Seropedica, RJ - Brasil

\section{JOSÉ AUGUSTO VEIGA DA COSTA MARQUES}

Universidade Federal do Rio de Janeiro

FACC - Faculdade de Administração e Ciências Contábeis.

Av. Pasteur, 250 - Depto de Contabilidade/FACC/UFRJ - Urca

22290-240 - Seropedica, RJ - Brasil 